\title{
The Ontogeny of Somatic Embryos from in vitro Cultured Grapevine Anthers*
}

\author{
D.J. Newton and P.G. Goussard
}

Department of Viticuiture, University of Stellenbosch, 7600 Stellenbosch, Republic of South Africa

Submitted for publication: June 1990

Accepted for publication: October 1990

Key words: Vitis rupestris, grapevine, somatic embryogenesis, in vitro, ontogeny

\begin{abstract}
Translucent light green to yellow anthers excised from Vitis rupestris cv. Rupestris du Lot flower buds, produced from cuttings grown in a climate-controlled room, produced somatic embryos when cultured on modified Nitsch \& Nitsch (1969) medium supplemented with $1 \mu \mathrm{M}$ 6-benzylaminopurine (BAP) and $5 \mu \mathrm{M}$ 2,4-dichlorophenoxyacetic acid (2,4-D). Anatomical features of developing embryogenic explants were studied at various intervals, before and after the start of in vitro culture, using light microscopy. Results indicated that callus was entirely of somatic origin. Embryogenic cells were apparently present before in vitro culture commenced and multiplied sufficiently within the first $\mathbf{1 5}$ days' culture to form visible embryogenic growth centres. Embryogenic callus formed from the lateral and abaxial walls of the anther, all connective tissues and the filament. Somatic embryos were observed after 60 days of culture and possessed primordial vascular tissues and secondary embryoids. No vascular connections between somatic embryos were observed.
\end{abstract}

Anatomical and morphological studies of grapevine anthers giving rise to embryogenic callus are essential for establishing the characteristics and origin of embryogenic cells and the subsequent ontogenic developmental sequences leading to the formation of somatic embryos. Some anatomical and morphological characteristics of grapevine embryogenic callus and somatic embryos have been described by Mullins \& Srinivasan (1976), Krul \& Worley (1977), Rajasekaran \& Mullins (1979), Rajasekaran \& Mullins (1983), Krul (1985) and Gray \& Mortensen (1987). However, reports of detailed sequential anatomical studies are lacking.

The aims of this study, utilising excised anthers of $V$. rupestris cv. Rupestris du Lot, were to investigate (1) the origin of callus tissue giving rise to embryogenic tissues and somatic embryos, and (2) the anatomical and morphological ontogeny of callus and somatic embryos.

\section{MATERIALS AND METHODS}

Plant material: Dormant material of $V$. rupestris cv. Rupestris du Lot was collected from the University of Stellenbosch vineyard Welgevallen and stored in plastic bags containing perlite moistened with a one percent captan $(\mathrm{m} / \mathrm{v})$ solution at $4^{\circ} \mathrm{C}$. When floral material was required two to five node cane sections, with only the apical bud remaining, were placed upright in beakers containing a small volume of water at a temperature of $25 \pm 2^{\circ} \mathrm{C}$ in a climate-controlled growth chamber. Within two to four weeks the bud developed to produce a vigorously growing shoot. Flower development was promoted by removal of vegetative tissues (Mullins, 1966).

Surface sterilisation: Grapevine inflorescence were sterilised for $15 \mathrm{~min}$. in a seven percent $(\mathrm{m} / \mathrm{v})$ filtered solution of calcium hypochlorite $\left(\mathrm{Ca}(\mathrm{OCl})_{2}\right)$ containing 0,1 percent $(\mathrm{v} /$ v) Tween 20 wetting agent. After sterilisation, plant material was rinsed three times in sterile distilled water.

Explants: Anthers isolated from unopened flower buds were translucent light green to yellow in colour and 0,5 to 0,8 mm long.

Incubation conditions: For cultures in liquid medium, the clustered anthers of five flowers ( 25 anthers) were placed into $100 \mathrm{~m} l$ jelly jars containing $15 \mathrm{~m} l$ liquid medium. The liquid medium was agitated continuously on a rotary action shaking apparatus at 80 r.p.m. All containers were sealed with Parafilm M. Anthers were cultured in continuous darkness at $25 \pm 2^{\circ} \mathrm{C}$. After 30 days, liquid cultured anthers were transferred to the surface of solid medium of the same nutrient and growth regulator composition.

Culture media: The medium utilised was that of Nitsch \& Nitsch (1969) as modified by Rajasekaran \& Mullins (1979) and with the further modifactions of $219 \mathrm{mg} / l \mathrm{CaCl}_{2} \cdot 6 \mathrm{H}_{2} \mathrm{O}$ in place of $166 \mathrm{mg} / l ; 368 \mathrm{mg} / l \mathrm{KH}_{2} \mathrm{PO}_{2}$ in place of $68 \mathrm{mg} / l$ and $19 \mathrm{mg} / \mathrm{l} \mathrm{MnSO}_{4} \mathrm{H}_{2} \mathrm{O}$ in place of $25 \mathrm{mg} / \mathrm{l}$. Where required, liquid medium was solidified using $7 \mathrm{~g} / \mathrm{l}$ Difco Bacto agar. Both liquid and solid media were supplemented with $20 \mathrm{~g} / \mathrm{l}$ sucrose. Media utilised for the first three months of culture were supplemented with $1 \mu \mathrm{M}$ BAP and $5 \mu \mathrm{M} 2,4-\mathrm{D}$ but thereafter only basal medium without growth regulators was utilised. The $\mathrm{pH}$ of all media was adjusted to 5,5 prior to autoclaving.

Anatomical studies: Commencing with freshly excised anthers and thereafter at 15 day intervals anthers, anther callus and embryogenic tissue were withdrawn from culture and fixed in formalin-acetic acid - alcohol (FAA). Hematoxylin staining, used to asses the stage of pollen grain maturity, was done according to the method of Kindiger \& Beckett (1985).

\footnotetext{
* Part of a M.Sc (Agric.) thesis submitted by the senior author to the University of Stellenbosch.

Acknowledgements: Staff of the anatomical laboratory of the Department of Plant Pathology, University of Stellenbosch, and the SEM laboratory of the Fruit and Fruit Technology Research Institute, Stellenbosch, for technical assistance.
} 
Wax infiltration was by means of an automated tertiary butanol-paraffin wax procedure (Johansen, 1940). Sectioning was done using a rotating microtome. Sections $(10 \mu \mathrm{m})$ were stained with safranine and counterstained with fast-green and mounted onto microscope slides according to the technique of Johansen (1940). The sections were studied and photographed under an Olympus stereo photomicroscope.

\section{RESULTS AND DISCUSSION}

The anatomical structure of anthers prior to anthesis is shown in Fig. 1. In all sections (of anthers), bisporangiate sets of locules were revealed. The epidermal cells were small, thick walled (Fig. 1) and were lightly stained, indicating that the cells had a rich cytoplasmic content and little secondary wall development. The young and vigorous nature of the epidermal cells may enable them to form embryogenic callus. Immediately beneath the epidermis, a layer of cells occurred which were stained red in lighter and darker bands characteristic of endothecium cells which make up the endothecium.

The interlocular tissues, surrounding the filament attachment zone, stained dark red and were composed of large, thinwalled cells. The intensity of the staining suggests the presence of mainly mature cells. Cells producing embryogenic callus may have arisen from amongst the stained cells and/or from deeper cell layers. The pollen grains were packed predominantly in triad clusters with an occasional tetrad cluster occurring. Staining with hematoxylin revealed that the majority of pollen grains were in the uninucleate stage of development (not shown).

Vascular tissues in the filament were surrounded by parenchyma-like cells which in turn were enclosed by the epidermis. The cuticle of the filament was not visible with the techniques that were applied in this research. As illustrated in Fig. 1, the vascular tissues end blindly at the point of attachment to the interlocular tissues, and are succeeded by parenchymatic tissues.

After 15 days' culture, the interlocular tissues had expanded by cell division and forced the locules apart (Fig. 2). Callus formation took place from tissues on and around the filament attachment zone, the filament and epidermal cells of the anther. The filament often became swollen at the proximal end, which was followed by callus formation. This is in agreement with the results of Rajasekaran \& Mullins (1983). Occasionally the lightly stained and young cells of the filament would give rise to embryogenic tissues although no typical embryogenic cells were initially visible. Tissues were judged to be embryogenic by comparing the lightly stained, thickwalled, small-celled, cytoplasmic cells which had appeared in the interlocular tissues (Fig. 2) to embryogenic calli formed in later stages. If embryogenic cells existed in freshly excised anthers, they would only become visible after a period of cell division and growth to form embryogenic cell clusters. In support of this premise, embryogenic callus was only observed after 15 days of culture. The difference between parenchymatic and smaller cytoplasmic (embryogenic) cells was apparent at this early stage. Embryogenic callus originated either from the proximal or distal part of the filament and/or the parenchymatic tissues in the interlocular zone and/or the epidermal cells of the anther wall. No callus tissue was observed to form from the adaxial wall of the anther. The endothecium was not visible after 15 days' culture (Fig. 2) and the pollen grains had separated from each other.

After 30 days' culture, pollen grains were not observed to undergo cell division, however, some were lightly stained indicating that they were still viable. This result agrees with Rajasekaran \& Mullins (1983) who noted that pollen grains did not contribute to callus formation. The volume of embryogenic callus arising from somatic tissues had increased and embryogenic callus was present but had not taken on any organised form (Fig. 3). Embryogenic cells were small and densely cytoplasmic and lightly stained. Embryogenic callus was present in large firm growth centres (Fig. 4). Disintegration of the growth centres had commenced and pro-embryogenic mass (PEM) clusters had developed (Fig. 5). The existence of growth centres in embryogenic callus of the grapevine was first reported by Krul and Worley in 1977. Pro-embryogenic mass clusters composed of approximately 5 to 50 cells were observed. It was not within the scope of this research to prove that the PEM's arose out of single embryogenic cells due to the technical difficulties involved in observing the sequential development of single living embryogenic cells as reported by George \& Sherrington (1984).

Embryogenic callus was associated with either living parenchyma or necrotic cells and appeared to arise out of or near to parenchymatic cells which only turned necrotic subsequent to embryogenic callus formation (Fig. 3). This is contrary to the theory of Krul and Worley (1977) who regarded the presence of necrotic cells as possibly stimulating embryo formation.

After 45 days' culture all pollen grains appeared to be necrotic. Anthers cultured on solid initiation medium had formed cytoplasmically dense callus by this time and hence were 15 days behind liquid cultured anthers in development. The callus arising from solid culture was interspersed with necrotic disintegrated tissues, possibly as a result of the poor nutrient conductivity within the medium as suggested by George \& Sherrington (1984). There was no growth centre development in callus tissue which formed from anthers cultured on solid initiation medium.

The section illustrated in Fig. 6 shows a tissue type (LC) which developed in liquid initiated cultures. The cells of this tissue were slightly larger than embryogenic tissues located between the PEM and parenchymatic cells (PC). Only cytoplasmic staining of the LC cells occurred, indicating cellular juvenility. Parenchymatic tissues appeared to have produced the LC cell type which in turn may have generated the embryogenic tissues. The origin of a growth centre (EC) from within a cluster of parenchymatic cells is also illustrated. Embryogenic growth centres arise through cell division and with growth force their way out of the encircling parenchymatic cells. The pressure on the parenchyma cells may cause them to turn necrotic and hence the relationship noted by Krul \& Worley (1977) between growth centres and necrotic cells.

After 60 days' culture, the proportion of original parenchymatic tissue was much reduced compared to the volume of embryogenic tissues. The remains of a filament with embryogenic and parenchymatic callus developing at both ends is shown in Fig. 7, although a globular somatic embryo is only present at one end. The filament has not 


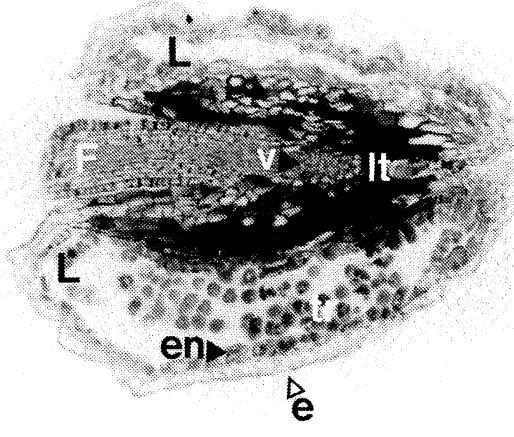

FIGURE 1

Cross section of $V$. vinifera cv. Rupestris du Lot anther before culture with pollen grains in the uninucleate stage of development, showing pollen grains clustered in triad (tr) groups, the filament $(\mathrm{F})$ between the locules $(\mathrm{L})$ with lightly stained cell walls. Vascular tissues (v) in the filament terminate at attachment to interlocular tissues (arrowed). The epidermis (e) is lightly stained suggesting rich cytoplasmic content and high regenerative abilities. Under the epidermis is the endothecium (en), with light and dark stained bands of secondary wall deposits. Interlocular tissues (It) are heavily stained implying maturity or necrotic nature of the cells. (900 X).

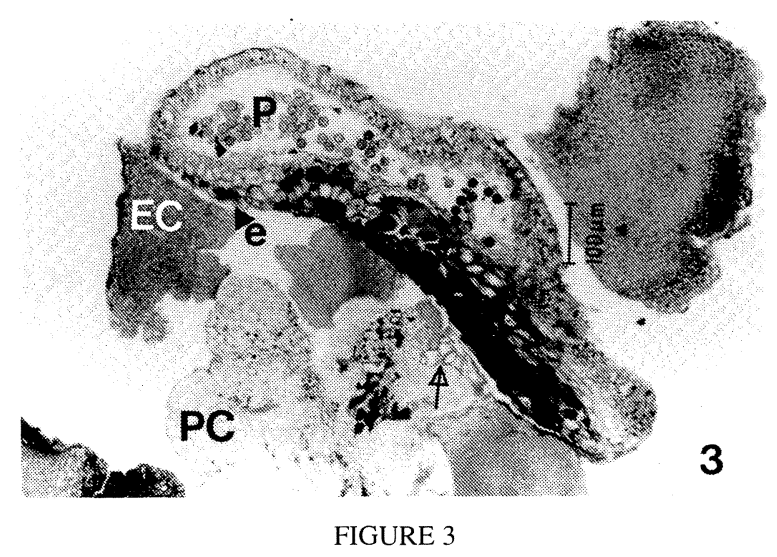

Cross section of anther, 30 days after culture initiation, showing pollen grains (P) enclosed in locule (without any cell division) and embryogenic tissues (EC) associated with epidermis cells (e). Embryogenic tissues have stained nuclei and cytoplasm rather than stained cell walls as the parenchymatic cells (PC) possess. Arrow indicates EC with PC layer on one side.

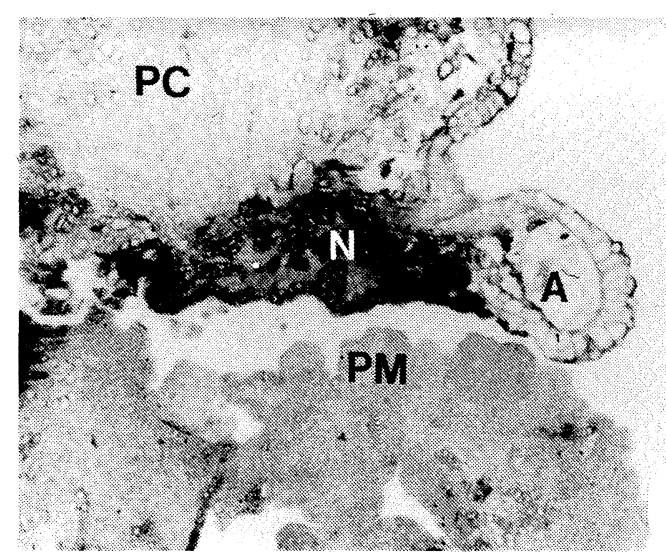

5

\section{FIGURE 5}

Longitudinal section of anther, 30 days after culture initiation, showing anther (A) with necrotic tissue (N), PEM (PM) and non-embryogenic callus (PC) developing out of anthers base. Cell walls of PM are not easily distinguishable due to small size of the cells. (1131 X).

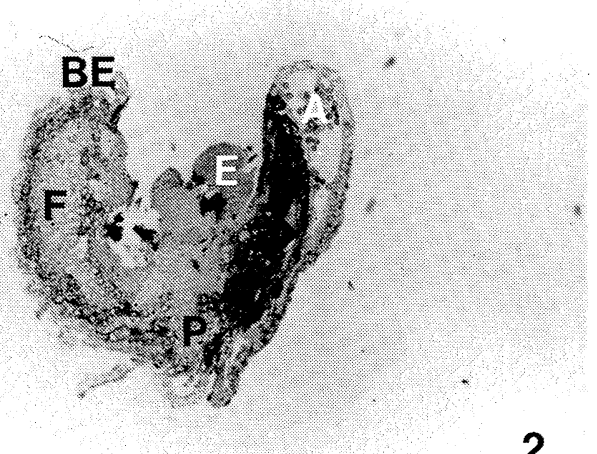

FIGURE 2

Longitudinal section of anther, 15 days after culture initiation showing parenchymatic callus $(\mathrm{P})$ and possible embryogenic callus (E) development out of anthers base (A) and the proximal end of the filament $(F)$. Note the swollen and dedifferentiated condition of the filament at basal end (BE). $(470 \mathrm{X})$.

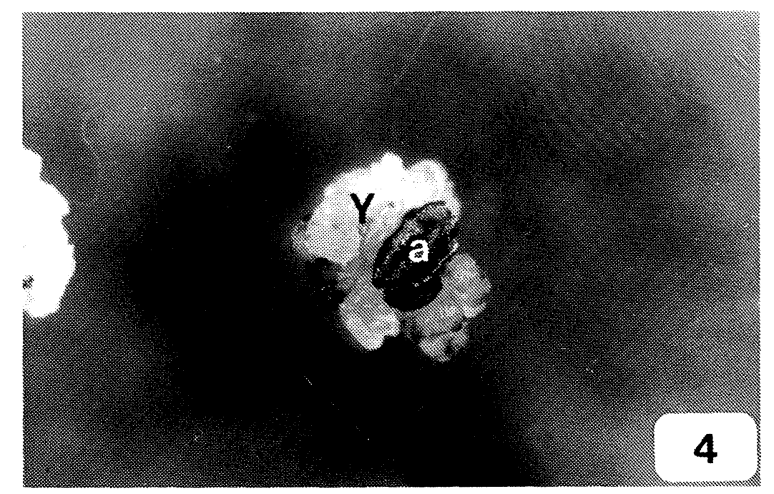

FIGURE 4

View of non-friable, pale yellow nodular callus $(\mathrm{Y})$ at 30 days after the start of culture. The anther (a) is present and yellow callus protrudes from its base. $(13.3 \mathrm{X})$.

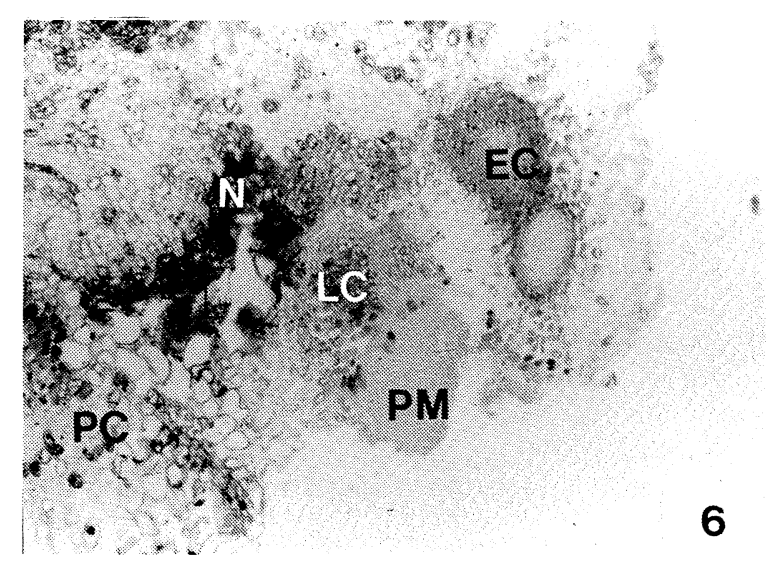

FIGURE 6

Longitudinal section, 45 days after culture initiation showing origin of PEM (PM) out of slightly larger cells (LC) with stained walls and/or stained cytoplasm. Very large parenchyma cells (PC) are shown for comparison. Within the PEM there is no tissue differentiation. The PEM cluster is separated from the necrotic cells (N). Embryogenic callus (EC) growth centre enclosed by $\mathrm{LC}$ also visible. 


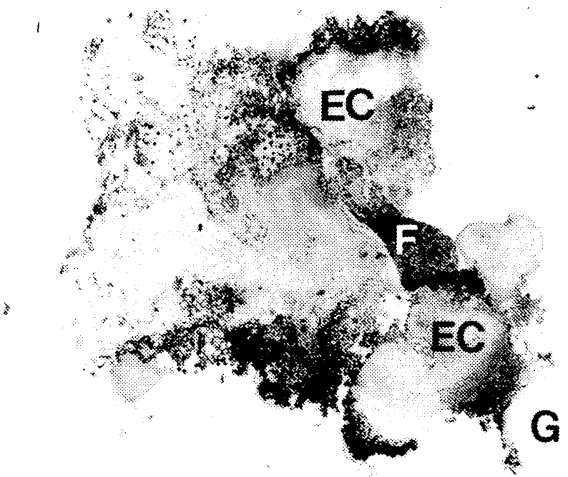

FIGURE 7

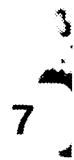

Longitudinal section of anther filament (F), 60 days after culture initiation showing embryogenic callus (EC) at both ends. One globular embryo is present (G) having developed out of darkly stained but small celled tissues. The procambial tissues are arrowed. All the EC is surrounded entirely or partly by necrotic callus. ( $80 \mathrm{X})$.

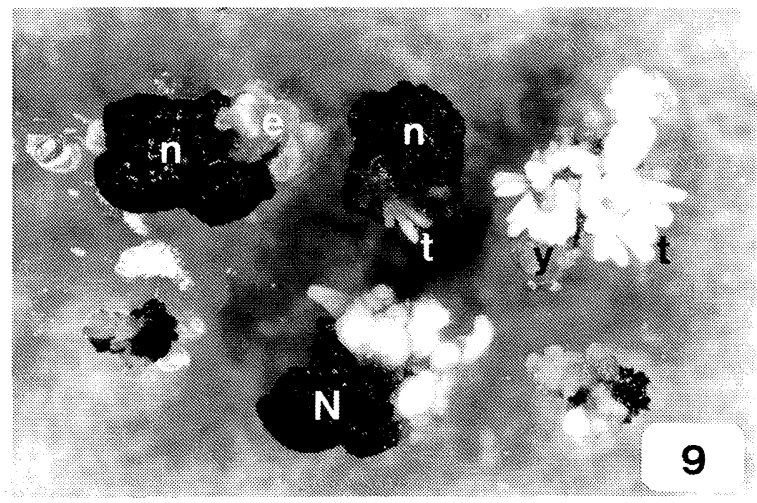

FIGURE 9

View of embryogenic callus cluster 75 days after culture initiation showing torpedo stage embryoids ( $\mathrm{t}$ ). Only $25 \%$ to $50 \%$ of the necrotic friable callus $(\mathrm{n}$ or $\mathrm{N}$ ) remains while the rest of the cluster is embryogenic (e). The yellow, non friable callus (y) is almost entirely embryogenic. (6.9 X).

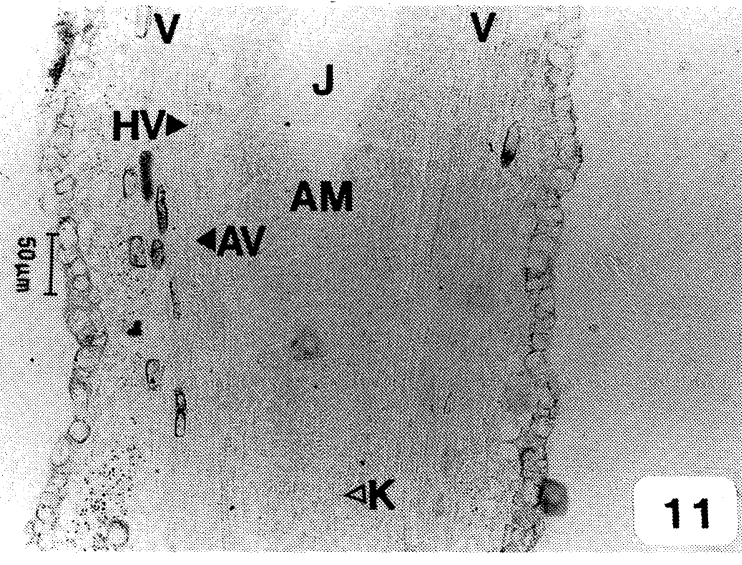

FIGURE 11

Longitudinal section of somatic embryo 90 days after culture initiation showing red-stained nuclei and pink nucleolus $(\mathrm{K})$ in the apical meristem (AM) region. Annular (AV) and helical vessels (HV) are present. Vascular (V) tissues of both cotyledons are visible on either side of the AM region. The junction of the cotyledons is indicated $(\mathrm{J})$.

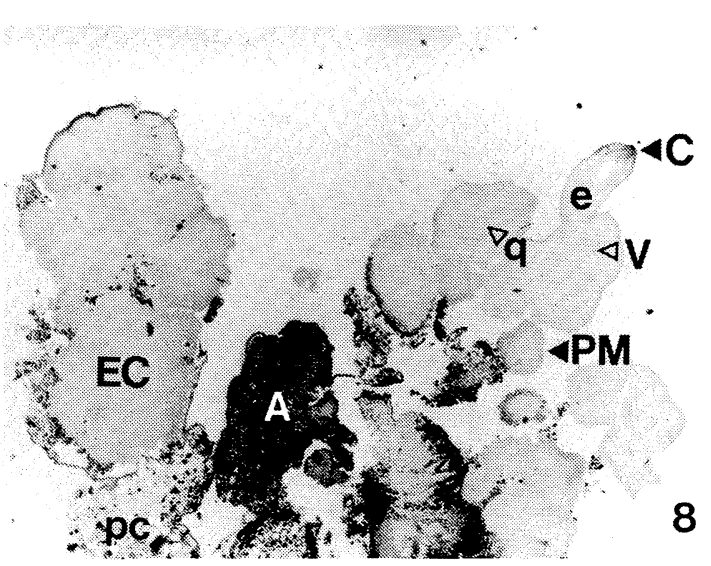

FIGURE 8

Cross section, 60 days after culture initiation showing necrotic remains of anther (A), parenchymatic tissues (pc) embryogenic callus (EC), PEM (PM) and somatic embryos (e). Necrotic tissues partly surround the EC. Procambial vascular tissues (v) and cotyledons (C) of embryos are present and the quiescent centre (q) of the somatic embryo is visible. (87 X).

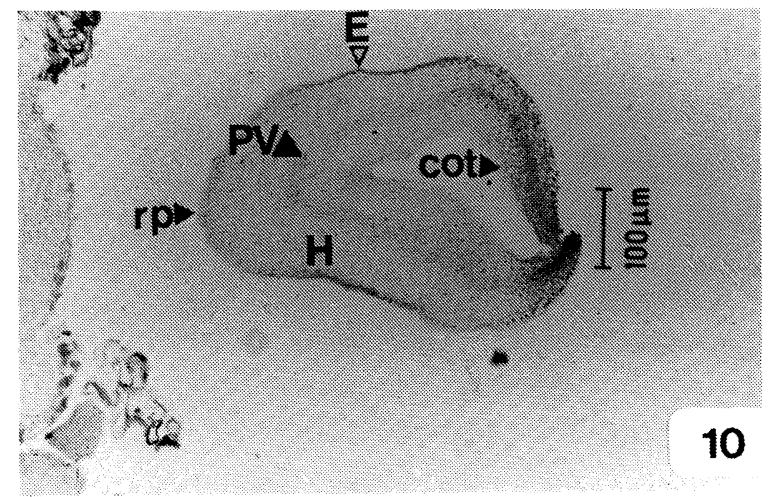

FIGURE 10

Longitudinal section of mature somatic embryo, 90 days after culture initiation, showing epidermis (E), hypodermis $(\mathrm{H})$, primordial vascular tissues (pv) and cotyledons (cot). The root pole (rp) is not well-developed and very short. (986 $\mathrm{X})$.

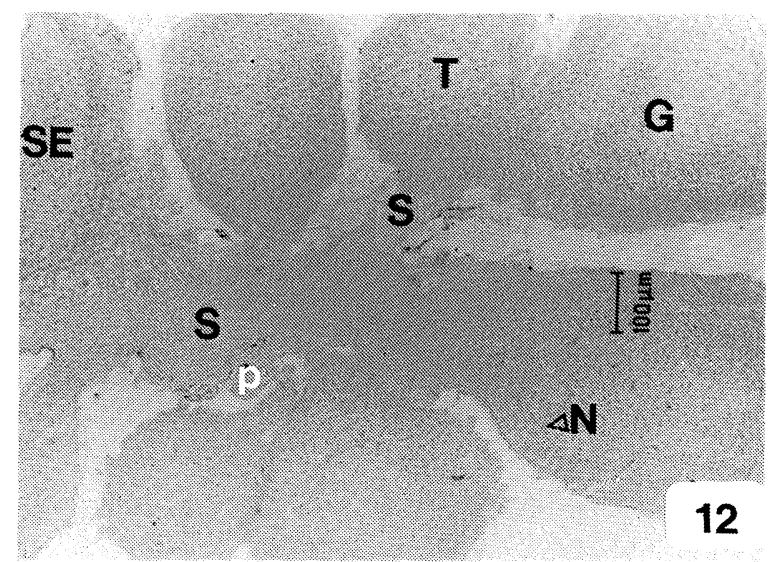

FIGURE 12

Longitudinal section, 105 days after culture initiation showing mature somatic embryo (SE) with suspensor-like (S) organ. The stained nuclei $(\mathrm{N})$ are prominent and there is no sign of vascular connections between the embryoids. A developing suspensor is visible between the secondary $(\mathrm{G})$ and tertiary $(\mathrm{T})$ embryo. Primordial secondary embryos (p) are developing out of the primary suspensor. 
previously been reported to form embryogenic callus (Rajasekaran \& Mullins, 1983).

Anther remains (necrotic) were still visible in some sections (Fig. 8) surrounded by necrotic parenchyma, embryogenic callus, PEM and somatic embryos. Immature xylem ring vessels first appeared in globular and torpedo stage embryoids at this stage. Similarly, Gray \& Mortensen (1987) first noted secondary tissues in globular and torpedo stage embryos. It is doubtful that necrotic tissues play a role in stimulating somatic embryogenesis as it was only the undifferentiated non-friable embryogenic callus (from which the PEM developed) that was surrounded by necrotic tissues. Somatic embryos differentiated only after PEM callus had formed from the embryogenic callus, and when the PEM callus was free of necrotic tissue borders (Fig. 8). Root and hypocotyl poles were well developed at the torpedo stage of embryo development and secondary embryo formation commonly occurred out of the hypocotyl/root zone of these existing embryoids. The embryos only developed a suspensor as the procambial tissues differentiated. This is contrary to Gray \& Mortensen (1987) and Krul \& Worley (1977) who established that primary embryos formed via suspensor-like structures out of the PEM callus. Sections of globular somatic embryos show a central quiescent centre surrounded by thin bands of procambial vascular tissues undergoing intense cell division. Bands were continuous from the root pole to the tip of the future cotyledons (Fig. 8).

After 75 days' culture the clusters of embryogenic callus, PEM and somatic embryos arising from explants initially cultured in liquid medium had enlarged and the proportion of necrotic tissue present was smaller (Fig. 9). However, the tissues cultured on solid initiation medium were still in the preliminary stages of embryogenic callus formation. Somatic embryos and PEM callus of embryogenic cultures, initiated in liquid medium, appear as depicted in Fig. 9. From this stage onwards, there were few new ontogenic developments, as mature embryos had been formed after 60 days of culture. The only notable changes were the increase in size of the somatic embryo cluster, the formation of secondary embryos and the maturing of vascular tissues.

After 90 days' culture, clusters of embryogenic callus, PEM callus and somatic embryos (up to mature stage) were expanding and necrotic tissues (including the anther and parenchymatic tissues) were present in a small proportion. Mature somatic embryos possessed well developed cotyledons, a root pole and primary vascular tissues (Fig. 10). In this research and in that of Mullins \& Srinivasan (1976), Gray \& Mortensen (1987) and Krul \& Worley (1977), abnormal embryo formation was a regular occurrence. Mullins \& Srinivasan (1976), and Krul \& Worley (1977) found that most somatic embryos produced were squat and possessed short hypocotyls which were surmounted by normal or deformed cotyledons. In this research, the epidermis of the embryoids appeared rough and uneven as if dedifferentiating. In anatomical sections, the unevenness of the epidermis was apparent (Fig. 10) but there was no indication as to the cause of the abnormality.

A view of the apical meristem area between the cotyledons is presented in Fig. 11. This area has been likened by Mullins
\& Srinivasan (1976) to the gemmule of zygotic embryos. The closely spaced, small, thick-walled and densely cytoplasmic cells with red stained nuclei and pink stained nucleoli are visible. Despite the intense cell division in the apical meristem area, shoot formation from the embryoids rarely occurred. The intensive cell division between the cotyledons may be associated with shoot formation but could help to separate the cotyledons by forcing them apart as occurs before germination. The epidermis and hypodermis of the somatic embryos is also illustrated in Fig. 11. Vascular tissues occurred under the hypodermis and consisted of xylem vessels with annular and helical wall thickenings (ring and helical vessels). Only ring and helical vessels were present in the vascular bundle after three months' culture.

After 105 days' culture, the remains of the anther and other necrotic and living parenchymatic tissue were still visible. Some clusters of necrotic calli had not developed embryogenic callus. Embryogenic callus and PEM tissues were constantly being formed. Simultaneously, mature and immature somatic embryos were producing secondary embryos. Secondary somatic embryos usually formed out of the base of mature or immature embryos (Fig. 12). Somatic embryos matured unevenly and no predominant stage of maturity was present.

Secondary embryoids were usually attached to the root axis extension of the parent embryo, by a suspensor-like structure but there was no common vascular connection. Suspensorlike attachments only became visible as the globular embryos grew larger and developed their own procambial tissues (Fig. 12). Where the embryos were tightly packed, there appeared to be no suspensor (Fig. 12) but budding embryos were normally easily separated, which demonstrates the lack of vascular links with other embryos.

Primordial embryos (Fig. 12) developed out of epidermal cells of the hypodermis/radicle transition zone. The elongated cells of the cambial tissues in the radicle were not observed to be involved in embryo formation.

\section{CONCLUSIONS}

Anthers sectioned before culture possessed cells (mainly epidermal) that were small, thick-walled and densely cytoplasmic. These were possibly precursor embryogenic cells, as a similar type of cell was observed in embryogenic growth centres which had developed after 15 days. Embryogenic cells arose from the abaxial side of the anther, the lateral walls of the anther, the filament and all connective tissues between the locules. It is possible therefore, that embryogenic cells are always present and simply require suitable culture conditions to stimulate cell division and subsequently growth centre formation. Pro-embryonic mass clusters were visible devel-. oping out of the growth centres after 30 days of culture and had also commenced fragmentation. The PEM clusters multiplied and fragmented further up to 60 days after culture initiation by which time the first somatic embryos had differentiated. From 60 days onwards, secondary vascular tissues had developed sufficiently to be visible. Secondary and tertiary embryos developed out of the hypocotyl/radicle transition zone of the parent somatic embryos.

Sometimes the radicle was elongated into a suspensor-like organ and secondary embryos developed out of the epidermal 
cells of this structure. There was no visible vascular connection between any two neighbouring embryoids. The lack of vascular contact between embryoids substantially reduces the possibility of the spread of certain harmful virus particles (i.e. those normally restricted to vascular tissues) from infected tissues to rapidly proliferating tissues or somatic embryos and indicates that virus elimination using somatic embryogenesis may be feasible.

\section{LITERATURE CITED}

GEORGE, E.F. \& SHERRINGTON, P.D., 1984. Plant propagation by tissue culture. Handbook and directory of commercial laboratories. Basingstoke: Exegetics Ltd.

GRAY,D.J. \& MORTENSEN, J.A., 1987. Initiation and maintenance of long term somatic embryogenesis from anthers and ovaries of Vitis longii "Microsperma". Plant Cell, Tissue and Organ Culture 9, 73-80.

JOHANSEN, D.A., 1940. Plant Microtechnique. New York: McGraw-Hill, Inc.
KINDIGER, B. \& BECKETT, J.B., 1985. A hematoxylin staining procedure for maize pollen grain chromosomes. Stain Tech. 60, 265-269.

KRUL, W.R., 1985. Somatic embryo initiation, induction and development. Proc. Colloque amelioration de la vigne et culture in vitro. Paris, 101-120.

KRUL, W.R. \& WORLEY, J.F., 1977. Formation of adventitious embryos in callus cultures of "Seyval", a French hybrid grape.J.Am.Soc. Hortic. Sci. 102, 360-363.

MULLINS, M.G., 1966. Test plants for investigations of the physiology of fruiting in Vitis vinifera L. Nature (London) 209, 419-420.

MULLINS. M.G. \& SRINIVASAN, C., 1976. Somatic embryos and plantlets from an ancient clone of grapevine (cv. Cabernet Sauvignon) by apomixis in vitro. J. Exper. Bot. 27, 1022-1030.

NITSCH, J.P. \& NITSCH, C., 1969. Haploid plants from pollen grains. Science 163, 85-87.

RAJASEKARAN, K. \& MULLINS, M.G., 1979. Embryos and plantlets from cultured anthers of hybrid grapevines. J. Exper. Bot. 30, 399-407.

RAJASEKARAN, K. \& MULLINS, M.G., 1983. The origin of embryos and plantlets from cultured anthers of hybrid grapevines. Am. J. Enol. Vitic. 34, 108-113. 